\title{
DENTAL EROSION AS A MANIFESTATION OF SJOGREN'S SYNDROME
}

\author{
Mayya Koleva, Vesela Hristova, Maya Doychinova, Genoveva Balcheva \\ Department of Conservative Dentistry and Oral Pathology, Faculty of Dental Medicine, \\ Medical University of Varna
}

\begin{abstract}
INTRODUCTION: Dental erosion is the loss of dental hard tissue by a chemical process not involving bacteria. It has a multifactorial origin and could be observed as a manifestation of different diseases such as Sjogren's syndrome.

MATERIALS AND METHODS: The article reports a clinical case of a 57-year-old patient with erosive defects on the entire dentition and problems with saliva secretion.

Diagnosis was made by using ultrasound examination and chairside test for evaluation of saliva properties.

RESULTS: The results from the chairside test revealed poor quality of the stimulated and resting saliva. The ultrasound examination showed a total change in the structure of the tissues of all salivary glands.

CONCLUSION: Dental health should not be treated as an isolated body condition - it is part of the whole organism. The intraoral examination can be essential for the discovery of some systemic diseases.
\end{abstract}

Keywords: tooth erosion, Sjogren's syndrome, salivary flow

\section{INTRODUCTION}

Dental substance loss due to erosion is an increasing problem for many patient groups (1-3).

Tooth erosion is the loss of tooth substance by chemical processes, as result of dental surface exposure to acids of extrinsic or intrinsic origins, without the involvement of bacteria (4). This erosive wear is a multifactorial condition, and this is important to evaluate the potential factors which could lead to identification of persons at risk (5).

Address for correspondence:

Mayya Koleva

Faculty of Dental Medicine

Medical University of Varna

84 Tsar Osvoboditel Blvd

Varna

e-mail:maija_koleva@abv.bg

Received: May 10, 2017

Accepted: June 13, 2017
The increased acidity which harms the tooth surfaces is sometimes related to the lifestyle but sometimes it is a result of different diseases, which affect the quality and quantity of the saliva.

Saliva is considered the most important biological factor preventing dental erosion (6). It protects against dental erosion due to its many properties, which include dilution and clearance of an erosive agent from the mouth; neutralization and buffering of dietary acids; formation of the acquired pellicle that protects the enamel surface from demineralization by dietary acids; and provision of calcium, phosphate and possibly fluoride, which are necessary for remineralization (7).

The intraoral symptoms and signs of Sjogren's syndrome are not specific to it, being shared with other conditions in which salivary function is diminished. The decrease in saliva causes chronic oral discomfort and functional problems and predisposes patients to dental caries (8) and tooth wear. 
Mayya Koleva, Vesela Hristova, Maya Doychinova et al.

A case of a patient suffering from Sjogren's syndrome with significant loss of dental structure is reported.

\section{MATERIALS AND METHODS}

A case of a 57-year-old woman with multiple defects on almost all vestibular surfaces of the teeth is reported. The patient complained of poor esthetics, dry mouth and burning sensation of the mucous.

\section{Examination findings}

During the extraoral examination a mild swelling in the area of the right parotid gland was a palpable.

The intraoral examination revealed facial defects on the entire dentition, with a width visibly exceeding their depth (Fig. 1, 2, 3). The process that affected the teeth was non-carious and destructive.

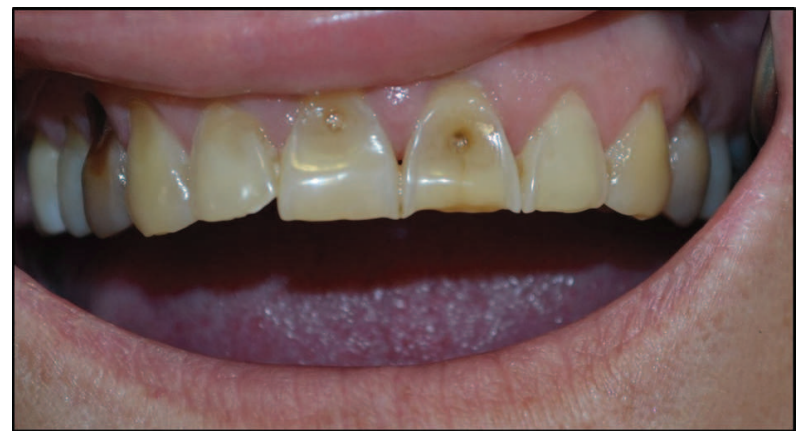

Fig. 1. Tooth erosion on the vestibular surfaces of the upper incisors

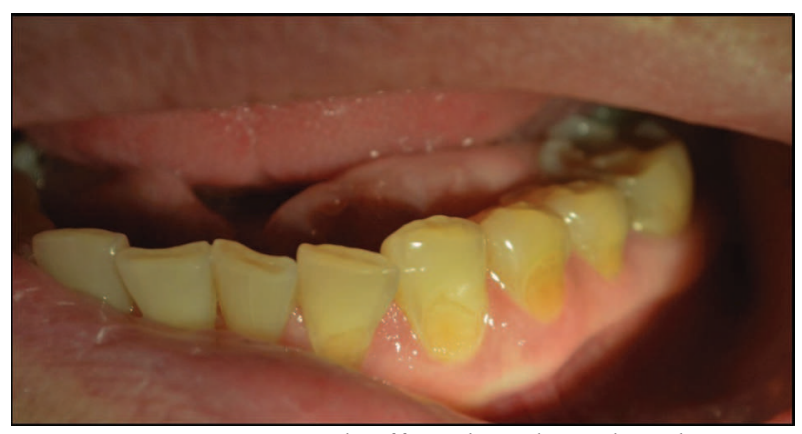

Fig. 2. Lower teeth affected on the right side

The amount of the saliva in the oral cavity was scarce, with frothy bubbly appearance. Tooth wear due to erosion was the possible diagnosis and problems with the salivary glands were suspected.

Confirmation of the diagnosis requires a detailed anamnesis and a complex of studies.

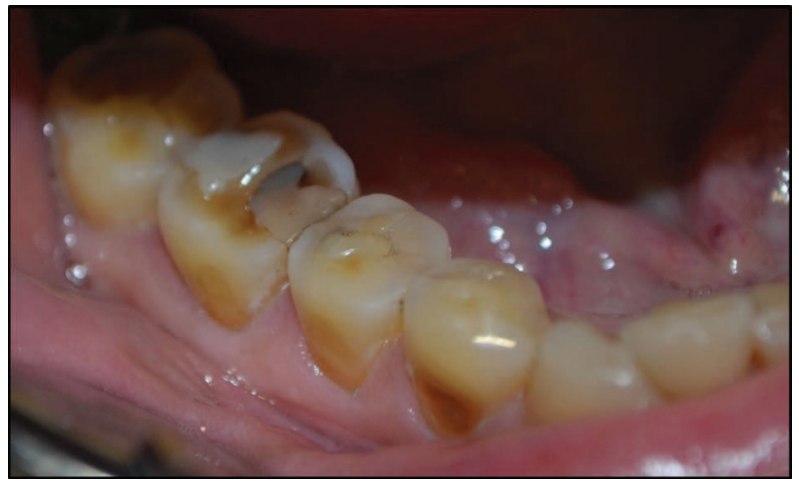

Fig. 3. Lower teeth affected on the left side

A detailed questionnaire was given to the patient, including questions about her eating and drinking habits.

By using GC Saliva-Check BUFFER kit (GC Europe) we examined the saliva quality, $\mathrm{pH}$ and buffering capacity. This is a simple in-office test for evaluating how well saliva protects the teeth. Saliva testing involves both the stimulated and unstimulated saliva. By evaluating both, the test results become very useful diagnostic and powerful communication tools (9).

The saliva test consists of the following five steps:

$\diamond$ Step 1 - resting saliva hydration

$\diamond$ Step 2 - resting saliva viscosity

$\diamond$ Step 3 - resting saliva $\mathrm{pH}$

$\diamond$ Step 4 - stimulated saliva quantity

$\diamond$ Step 5 - stimulated saliva buffering capacity (quality)

Because it was suspected that the patient had problems with the salivary glands, she was sent for ultrasound examination.

All the results indicated a diagnosis of tooth wear due to erosion.

As a guide to clinical management we have used the Basic Erosive Wear Examination (BEWE) system. The most severely affected surface in each sextant was recorded with a four level score and the cumulative score was classified and matched to risk levels, which guide the management of the condition. The four-level score (Table 1) graded the appearance or severity of wear on the teeth from no surface loss (0), initial loss of enamel surface texture (1), distinct defect, hard tissue loss (dentin) less than $50 \%$ of the 
Dental Erosion as a Manifestation of Sjogren's Syndrome

Table 1. Criteria for grading erosive wear

\begin{tabular}{cc} 
Score & No erosive tooth wear \\
0 & Initial loss of surface texture \\
1 & Distinct defect, hard tissue loss $<50 \%$ of the \\
$2^{*}$ & surface area \\
$3^{*}$ & Hard tissue loss $\geq 50 \%$ of the surface area \\
\hline
\end{tabular}

*in scores 2 and 3 dentine often is involved

surface area (2) or hard tissue loss more than $50 \%$ of the surface area (3). Buccal/facial, occlusal, and lingual/palatal surfaces were examined with the highest score recorded. The examination was repeated for all teeth in a sextant but only the surface with the highest score was recorded for each sextant (10). The sum of the scores was calculated and served to determine the severity of the condition. When transferred into risk levels it could be a possible guide towards management (10) (Table 2).
Because of the suspected problems with the parotid glands the patient was sent for ultrasound examination.

\section{RESULTS}

The outcomes from the Saliva-Check BUFFER kit revealed reduced salivary flow with low $\mathrm{pH}$ and low buffering capacity (Table 3).

A detailed questionnaire that included also dietary habits showed a long-standing excessive consumption of acidic fruits (for many years until noon every day the patient has consumed only fruits and mainly green apples).

All these examinations confirmed the diagnosis of tooth erosion.

As it was mentioned above as a guide to clinical management we have used BEWE, whereby we have assessed the risk level as high (Table 4).

The results from the ultrasound examination showed a total change in the structure of the tis-

Table 2. Risk levels as a guide to clinical management

\section{Risk level Cumulative score of all sextants}

None Less than or equal to 2a

Low Between 3 and $8 \mathrm{a}$

Medium $\quad$ Between 9 and 13a

High $\quad 14$ and over

\section{Management}

Routine maintenance and observation

Repeat at 3-year intervals

Oral hygiene and dietary assessment, and advice, routine maintenance and observation

Repeat at 2-year intervals

Oral hygiene and dietary assessment, and advice, identify the main aetiological factor(s) for tissue loss and develop strategies to eliminate respective impacts

Consider fluoridation measures or other strategies to increase the resistance of tooth surfaces

Ideally, avoid the placement of restorations and monitor erosive wear with study casts, photographs, or silicone impressions

Repeat at 6-12-month intervals

Oral hygiene and dietary assessment, and advice, identify the main etiological factor(s) for tissue loss and develop strategies to eliminate respective impacts

Consider fluoridation measures or other strategies to increase the resistance of tooth surfaces

Ideally, avoid restorations and monitor tooth wear with study casts, photographs, or silicone impressions

Especially in cases of severe progression consider special care that may involve restorations

Repeat at 6-12-month intervals 
Mayya Koleva, Vesela Hristova, Maya Doychinova et al.

Table 3. Patient results from the test

\section{UNSTIMULATED SALIVA}

Resting Flow Rate

(Visually assess the lower lip labial secretion)

Salivary Consistency (Visually assess the resting salivary consistency in the oral cavity)

pH - Resting Saliva
$>60 \mathrm{sec}$

Low

\section{Frothy bubbly saliva}

Increased viscosity

$\mathrm{pH} \approx 5,8$

Highly acidic saliva

\section{STIMULATED SALIVA}

Quantity - Stimulated
Saliva
(Volume of Saliva/Value)
$<3,5 \mathrm{~mL}$

Very low

$\mathrm{pH} \approx 5,8$

Highly acidic saliva

Table 4. Assessing the risk level of the patient by using the BEWE system

\begin{tabular}{|c|c|c|c|c|c|c|}
\hline $\begin{array}{l}\text { Highest grade } \\
\text { 1. Sextant }(17-14)\end{array}$ & 2 & $\begin{array}{l}\text { Highest grade } \\
\text { 2. Sextant (13-23) }\end{array}$ & 3 & $\begin{array}{l}\text { Highest grade } \\
\text { 3. Sextant ( } 24-27)\end{array}$ & 2 & \\
\hline $\begin{array}{l}\text { Highest grade } \\
6 . \text { Sextant }(44-47)\end{array}$ & 3 & $\begin{array}{l}\text { Highest grade } \\
5 \text {. Sextant (33-43) }\end{array}$ & 2 & $\begin{array}{l}\text { Highest grade } \\
\text { 4. Sextant ( } 37-34)\end{array}$ & 3 & Total Score: 15 \\
\hline & & & & & & $\begin{array}{l}\text { Risk Level: } \geq 14 \\
\text { High }\end{array}$ \\
\hline
\end{tabular}

sues of all salivary glands and confirmed Sjogren's syndrome.

\section{Treatment and Follow-up}

Due to lack of finances the patient received direct resin composite restorations of only some of the teeth and guidelines for changing the dietary and hygiene habits. We explained to the patient that routine maintenance and observation, repeated at 6- to 12-month intervals, were needed.

Because of Sjogren's syndrome treatment with corticosteroids was initiated. After a two-year break the patient decided to continue her dental treatment, but many of the erosive defects showed a significant progress (Fig. 4, 5). She had not followed strictly our recommendations but in regard to the main disease

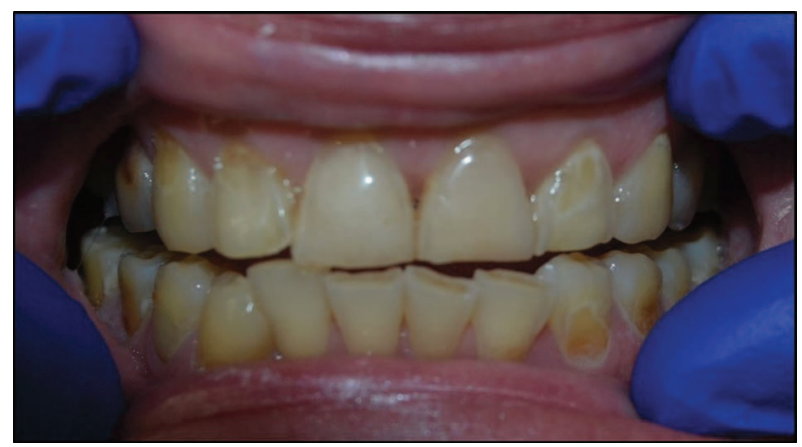

Fig. 4. After a two-year break
- the Sjogren's syndrome, she was conscientious and the treatment still continues.

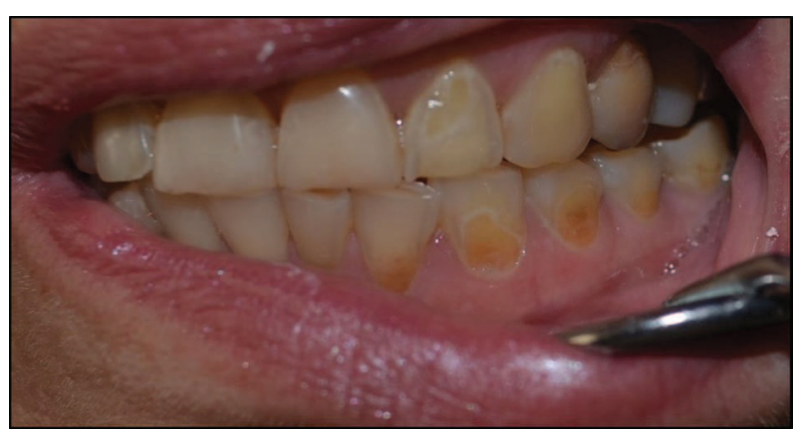

Fig. 5. After two years the defects are even greater

\section{CONCLUSION}

The processes in the human body are interrelated. Usually damage to one organ or system reflects on others. Usually tooth erosion has a multifactorial etiology, and for its diagnosis an interdisciplinary approach is needed. Sometimes the treatment is long and complex, and its success is impossible without strict and systematic care both from patient and clinician. 


\section{REFERENCES}

1. Al-Dlaigan YH, Shaw L, Smith A. Dental erosion in a group of British 14-year-old, school children. Part I. Prevalence and influence of differing socioeconomic backgrounds. Br Dent J. 2001; 190(3):145-9. doi: 10.1038/sj.bdj.4800908a

2. Dugmore CR, Rock WP. A multifactorial analysis of factors associated with dental erosion. Br Dent J. 2004; 196(5):283-6. doi: 10.1038/sj.bdj.4811041

3. Wiegand A, Muller J, Werner C, Attin T. Prevalence of erosive tooth wear and associated risk factors in 2-7-year-old German children. Oral Dis. 2006; 12(2):117-24. doi: 10.1111/j.1601-0825.2005.01167.x

4. Imfeld T. Dental erosion. Definition, classification and links. Eur J Oral Sci. 1996; 104(2):151-5. doi: 10.1111/j.1600-0722.1996.tb00063.x

5. Lussi A, Jaeggi T. Dental Erosion. Etiology and risk assessment. In: Diagnosis, Risk Assessment, Prevention, Treatment. London: Quintessence; 2011; pp. 37-53.

6. Lussi A, Schaffner M, Jaeggi T. Dental erosion-diagnosis and prevention in children and adults. Int Dent J. 2007; 57(6):385-98. doi: 10.1111/j.1875595X.2007.tb00166.x

7. Mandel ID. The functions of saliva. J Dent Res. 1987; 66(Suppl 1):623-7. doi: 10.1177/00220345870660S203

8. Daniels TE, Fox PC. Salivary and oral components of Sjogren's syndrome. Rheum Dis Clin North Am. 1992; 18(3): 571-89.

9. Ranganath LM, Shet RGK, Rajesh AG. Saliva: A Powerful Diagnostic Tool for Minimal Intervention Dentistry. J Contemp Dent Pract. 2012; 13(2):240-5.

10. Bartlett D, Ganss C, Lussi A. Basic Erosive Wear Examination (BEWE): a new scoring system for scientific and clinical needs. Clinical oral investigations. 2008; 12(Suppl 1): 65-68. doi: 10.1007/ s00784-007-0181-5 